\title{
PENGARUH UAP ROKOK ELEKTRIK TERHADAP KUALITAS UDARA AMBIEN PADA LINGKUNGAN PENGGUNA ROKOK ELEKTRIK DI KOTA PAREPARE
}

\section{The Influence of Electric Cigarette Vapor on Ambien Air Quality in Electric Cigarette User Environment in Parepare City}

Ardiyan Sabir, Muhammad Asikin, Ilham Willem

(Program Studi Kesehatan Masyarakat Fakultas Ilmu Kesehatan

Universitas Muhammadiyah Parepare)

(Hardiansabir11@gmail.com)

\begin{abstract}
ABSTRAK
Sumber pencemaran udara adalah hadirnya kontaminan di ruang terbuka dengan konsentrasi dan durasi yang sedemikian rupa, sehingga mengakibatkan gangguan, merugikan makhluk hidup dan menyebabkan kualitas udara tidak sesuai dengan peruntukannya. Kualitas udara terbagi menjadi dua, yaitu kualitas udara emisi dan kualitas udara ambien. Rokok elektrik adalah suatu perangkat dengan tenaga baterai yang menyediakan dosis nikotin hirup memberikan efek sama seperti merokok konvensional. Uap rokok elektrik yang keluar, tetap saja masuk ke dalam polusi udara. Walaupun tidak sebanyak asap yang keluar dari rokok tembakau konvensional biasa, namun uap yang dihasilkan oleh rokok elektrik juga bisa dikategorikan sebagai polusi udara. Tujuan penelitian ini untuk mengetahui pengaruh uap rokok elektrik terhadap kualitas udara ambien pada ruangan terbuka dan pada ruangan tertutup di lingkungan pengguna rokok elektrik Kota Parepare. Metode yang digunakan dalam penelitian ini adalah metode Quasy Eksperiment dengan desain penelitian one group pretest - post test. Peneliti mengidentifikasi melalui pengujian dengan menggunakan alat Yes Air kemudian dilakukan pencatatan ke dalam lembar observasi, dimana sampel dalam penelitian ini sebanyak 2 ruangan yaitu ruangan terbuka dan ruangan tertutup. Hasil penelitian menunjukkan bahwa ada pengaruh uap rokok elektrik terhadap kualitas udara ambien pada ruangan terbuka dan pada ruangan tertutup di lingkungan pengguna rokok elektrik Kota Parepare. Penelitian ini menyarankan kepada pengelola cafe hendaknya memasangan exhaust fan agar parameter pencemar udara tidak mengendap di dalam ruangan.

Kata Kunci : Uap rokok elektrik, kualitas udara, lingkungan pengguna rokok elektrik

\section{ABSTRACT}

The source of air pollution is the presence of contaminants in the open space with such concentration and duration, resulting in disruption, detrimental to living things and causing air quality not in accordance with its designation. Air quality is divided into two, namely air quality emissions and ambient air quality. Electric cigarette is a device with battery power that provides inhaled nicotine doses to have the same effect as conventional smoking. Electric cigarette vapors that
\end{abstract}


come out, still enter into air pollution. Although not as much as smoke coming out of conventional tobacco cigarettes, but the steam produced by electric cigarettes can also be categorized as air pollution. The purpose of this study was to determine the effect of electric cigarette vapor on ambient air quality in open spaces and in enclosed spaces in the electric cigarette users in Parepare City. The method used in this study is the Quasy Experiment method with one group pretest - post test research design. Researchers identified through testing using the Yes Air tool and then recorded it into an observation sheet, where the sample in this study were 2 rooms namely open space and closed room. The results showed that there was an effect of electric cigarette vapor on ambient air quality in open spaces and in enclosed spaces in the electric cigarette users of Parepare City. This research suggests that the cafe manager should install the exhaust fan so that the air pollutant parameters do not settle in the room.

Keywords : Electric cigarette steam, air quality, electric cigarette user environment 


\section{PENDAHULUAN}

Udara merupakan unsur yang sangat penting di dalam kehidupan manusia dan makhluk hidup lainnya. Setiap makhluk hidup membutuhkan udara untuk mendukung kehidupannya secara optimal, sehingga udara merupakan sumber daya alam yang harus dilindungi untuk kehidupan manusia dan makhluk hidup lainnya. Oleh karena itu udara merupakan komponen lingkungan yang sangat penting dalam kehidupan makhluk hidup, sehingga perlu dijaga dan dipelihara kualitasnya. Untuk mendapatkan udara sesuai dengan tingkat kualitas yang diinginkan, maka pengendalian kualitas udara menjadi sangat penting untuk dilakukan mengingat karena banyaknya pencemaran udara pada saat ini. ${ }^{3}$

Pencemaran udara diartikan dengan turunnya kualitas udara sehingga udara mengalami penurunan mutu dalam penggunaannya dan akhirnya tidak dapat dipergunakan lagi sebagaimana mestinya sesuai dengan fungsinya. Banyak faktor yang dapat menyebabkan pencemaran udara, salah satu faktor yang paling berdampak besar terhadap terjadinya pencemaran udara ialah hasil-hasil gas buangan dari kegiatan industri. Hasil dari gas buang industri tersebut berupa subtansi fisik seperti debu dan subtansi kimia seperti karbon monoksida dan sulfur dioksida. ${ }^{12}$

Sumber pencemaran udara adalah hadirnya kontaminan di ruang terbuka dengan konsentrasi dan durasi yang sedemikian rupa, sehingga mengakibatkan gangguan, merugikan makhluk hidup dan menyebabkan kualitas udara tidak sesuai dengan peruntukannya. Kualitas udara terbagi menjadi dua, yaitu kualitas udara emisi dan kualitas udara ambien. Kualitas udara emisi merupakan kualitas udara yang diukur secara langsung dari sumber emisi (cerobong pabrik, knalpot kendaraan bermotor) sedangkan kualitas udara ambien adalah kualitas udara yang diukur di udara bebas. ${ }^{9}$

Rokok elektronik atau rokok elektrik sedang menjadi fenomena baru di tengah masyarakat Indonesia. Belakangan ini kita tahu bahwa rokok elektronik mulai membanjiri pasar. Produsen mendaulat produknya itu tidak berbau dan lebih sehat ketimbang rokok konvensional. Rokok elektronik dianggap sebagai alat penolong bagi mereka yang kecanduan rokok supaya berhenti merokok. Alat ini dipasarkan sebagai alternatif yang lebih aman dari 
produk tembakau biasa. Label "HEALTH" pun terpasang jelas pada kemasannya. Namun hingga kini keberadaannya masih menuai kontroversi dan di sebagian besar negara dianggap sebagai produk yang ilegal dan terlarang. ${ }^{8}$

Rokok elektrik mengandung nikotin yang merupakan salah satu zat adiktif yang menimbulkan dampak kecanduan, dan juga menimbulkan perasaan mudah marah, depresi, gelisah, dan cemas. Hal ini berbahaya bagi orang yang menderita penyakit jantung. Sebuah penelitian menunjukkan bahaya rokok elektrik yang dilansir dari sciencenews, penelitian menunjukkan bahwa bahan kimia dalam rokok elektrik dapat merusak jaringan paru-paru dari kuman dan zat berbahaya lainnya. Hal ini karena kandungan nikotin dalam rokok menyebabkan sel paru-paru menjadi mudah ditembus oleh zat dari luar tubuh. ${ }^{11}$

Berdasarkan data dari The Tobacco Atlas 2015 yang dikutip oleh kompas.com Indonesia meraih peringkat satu dunia untuk jumlah pria perokok sebanyak 66 persen, peringkat kedua terbanyak yaitu Rusia dengan 60 persen, perigkat ketiga Cina 53 persen, peringkat keempat Filipina 48 persen dan peringkat kelima Vietnam 47 persen. Sungguh miris prevalensi perokok di Indonesia setiap tahunnya mengalami peningkatan baik perokok pria maupun wanita. Jumlah seluruh perokok di Indonesia diperkirakan lebih dari 90 juta orang yang mencapai sepertiga dari jumlah penduduk Indonesia. 5

Perilaku merokok penduduk 15 tahun ke atas masih belum terjadi penurunan dari 2007 sampai 2013. 64,9 persen laki-laki dan 2,1 persen perempuan masih menghisap rokok. Ditemukan 1,4 persen perokok umur 10 sampai 14 tahun, 9,9 persen perokok pada kelompok tidak bekerja dan 32,3 persen pada kelompok kuintil indeks kepemilikan terendah. ${ }^{7}$

Di Provinsi Sulawesi Selatan persentase penduduk umur 10 tahun ke atas yang merokok setiap hari 20,9 persen. Persentase tertingi ditemukan di Sinjai 24,5 persen, Tana Toraja 23,9 persen, Parepare 21,5 persen dan terendah dijumpai di Barru 15,4 persen. Prevalensi perokok saat ini tertinggi di Bantaeng 30,3 persen, Tana Toraja 29,3 persen, Sinjai 29,2 persen, Gowa 28,9 persen, Selayar 28,6 persen, Bone 27,8 persen, Luwu Timur 27,4 persen, Wajo 27,0 persen, Bulukumba 26,3 persen, Jeneponto 26,2 persen, Luwu 26,0 persen, dan Parepare 25,8 persen. $^{7}$ 
Uap rokok elektrik yang keluar, tetap saja masuk ke dalam polusi udara. Walaupun tidak sebanyak asap yang keluar dari rokok tembakau konvensional biasa, namun uap yang dihasilkan oleh rokok elektrik juga bisa dikategorikan sebagai polusi udara. Terlebih lagi, uap yang dihasilkan oleh rokok elektrik ternyata memiliki kandungan formalin dan senyawa karsinogenik, dimana akan sangat membahayakan tubuh terutama juga pada perokok pasif di sekitar anda. Uap dari rokok elektrik pun dianggap mengganggu lingkungan sekitar, sama seperti rokok tembakau. ${ }^{8}$

Maka berdasarkan latar belakang yang penulis uraikan di atas, penulis tertarik meneliti pengaruh uap rokok elektrik terhadap kualitas udara ambien pada lingkungan pengguna rokok elektrik di Kota Parepare.

\section{BAHAN DAN METODE}

Metode penelitian yang digunakan adalah metode Quasy Eksperiment dengan rancangan penelitian one group pretest post test. Populasi dalam penelitian ini adalah kualitas udara ambien di ruangan pengguna rokok elektrik. Variabel independen dalam penelitian ini adalah uap rokok elektrik sedangkan variabel dependennya adalah kualitas udara. Data primer diperoleh dari hasil pengujian dengan alat Yes Air. Data sekunder diperoleh dari hasil studi kepustakawan serta literatur-literatur yang terkait dengan objek penelitian. Data yang diperoleh berdasarkan pengujian dengan menggunakaan alat Yes Air dengan mengukur udara ambien ruangan tersebut sebelum perlakuan atau sebelum merokok di ruangan terbuka dan ruangan tertutup. Kemudian membandingkan setelah perlakuan atau setelah merokok di ruangan terbuka dan ruangan tertutup, selanjutnya kita catat dengan menggunakan lembar observasi.

\section{HASIL}

Penelitian ini dilakukan di Cafe Komunitas Vape Kota Parepare. Pengukuran kualitas udara ambien dilakukan pada hari Jumat tanggal 24 Agustus 2018 di ruangan ruangan terbuka yaitu YR Vapor dan di ruangan tertutup yaitu Anchor Vape. Pengukuran kualitas udara ambien dilakukan dengan menilai langsung hasil pengukuran dengan alat Yes Air menggunakan lembar observasi untuk mengetahui pengaruh uap rokok elektrik terhadap kualitas udara ambien di lingkungan pengguna rokok elektrik Kota 
Parepare. Waktu pengukuran sampel sebelum terpapar uap rokok elektrik dilakukan pukul 09.30 WITA pada ruangan tertutup dan pukul 10.30 pada ruangan terbuka atau pada saat cafe mulai terbuka. Dan waktu pengukuran sampel sesudah terpapar uap rokok elektrik dilakukan pukul 21.00 WITA pada ruangan tertutup dan pukul 22.00 pada ruangan terbuka atau pada saat cafe ramai pengunjung.

Hasil penelitian pada Tabel 1 menunjukkan bahwa pada ruangan terbuka gas SO2 sebelum terpapar 0,02 dan sesudah terpapar 0,04 ppm, gas NO2 sebelum terpapar 0,025 ppm dan sesudah terpapar 0,036 ppm, dan gas CO sebelum terpapar 1,05 ppm dan sesudah terpapar 2,093 ppm. Hasil penelitian pada Tabel 2 menunjukkan bahwa pada ruangan tertutup gas $\mathrm{SO} 2$ sebelum terpapar 0,02 ppm dan sesudah terpapar 0,03 ppm, gas NO2 sebelum terpapar 0,022 ppm dan sesudah terpapar 0,04 ppm, dan gas CO sebelum terpapar $0,97 \mathrm{ppm}$ dan sesudah terpapar 2,05 ppm.

Hasil penelitian pada Tabel 3 menunjukkan pengaruh uap rokok elektrik terhadap kualitas udara ambien di ruangan terbuka, dimana jumlah selisih sebelum dan sesudah dari gas SO2 sebanyak 0,02 ppm, gas NO2 sebanyak 0,011 ppm, dan gas CO sebanyak 1,043 ppm. Sedangkan untuk jumlah peningkatan pada gas $\mathrm{SO} 2$ sebanyak 50\%, gas $\mathrm{NO} 2$ sebanyak $30,56 \%$, dan gas CO sebanyak $49,83 \%$. Hasil penelitian pada Tabel 4 menunjukkan pengaruh uap rokok elektrik terhadap kualitas udara ambien di ruangan tertutup, dimana jumlah selisih sebelum dan sesudah dari gas SO2 sebanyak 0,01 ppm, gas NO2 sebanyak 0,018 ppm, dan gas CO sebanyak 1,08 ppm. Sedangkan untuk jumlah peningkatan pada gas $\mathrm{SO} 2$ sebanyak 33,33\%, gas NO2 sebanyak $45 \%$, dan gas CO sebanyak $52,68 \%$.

\section{PEMBAHASAN}

Ditinjau dari distribusi frekuensi pengaruh uap rokok elektrik terhadap kualitas udara ambien di ruangan terbuka pada tabel 4 menunjukkan bahwa jumlah selisih sebelum dan sesudah dari gas $\mathrm{SO} 2$ sebanyak 0,02 ppm, gas NO2 sebanyak 0,011 ppm, dan gas CO sebanyak 1,043 ppm. Sedangkan untuk jumlah peningkatan pada gas $\mathrm{SO} 2$ sebanyak $50 \%$, gas $\mathrm{NO} 2$ sebanyak $30,56 \%$, dan gas $\mathrm{CO}$ sebanyak $49,83 \%$.

Berdasarkan hasil pengukuran dengan menggunakan alat Yes Air diperoleh peningkatan antara sebelum 
terpapar uap rokok elektrik dan sesudah terpapar uap rokok elektrik, sehingga disimpulkan bahwa ada pengaruh uap rokok elektrik terhadap kualitas udara ambien pada ruangan terbuka di lingkungan pengguna rokok elektrik Kota Parepare.

Ditinjau dari distribusi frekuensi pengaruh uap rokok elektrik terhadap kualitas udara ambien di ruangan tertutup pada tabel 5 menunjukkan bahwa jumlah selisih sebelum dan sesudah dari gas $\mathrm{SO} 2$ sebanyak 0,01 ppm, gas NO2 sebanyak 0,018 ppm, dan gas CO sebanyak 1,08 ppm. Sedangkan untuk jumlah peningkatan pada gas SO2 sebanyak $33,33 \%$, gas NO2 sebanyak $45 \%$, dan gas CO sebanyak 52,68\%.

Berdasarkan hasil pengukuran dengan menggunakan alat Yes Air diperoleh peningkatan antara sebelum terpapar uap rokok elektrik dan sesudah terpapar uap rokok elektrik, sehingga disimpulkan bahwa ada pengaruh uap rokok elektrik terhadap kualitas udara ambien pada ruangan tertutup di lingkungan pengguna rokok elektrik Kota Parepare.

Menurut hasil observasi peneliti di lokasi penelitian pada saat sebelum terpapar uap rokok elektrik, cafe pada saat itu memang belum ada pengunjung, dan Air Conditioner (AC) sudah dinyalakan, hal ini menyebabkan udara dalam ruangan tersebut menjadi tersebar dan mengalami pengendapan. Hal ini sejalan sengan penelitian yang dilakukan oleh Prabu (2009) Angin dapat bekerja mengencerkan pencemar udara, sehingga dapat memperkecil bahaya dan kerugian akibat pencemar udara. Kondisi udara yang lembab akan membantu proses pengendapan bahan pencemar, sebab dengan keadaan udara yang lembab maka beberapa bahan pencemar berbentuk partikel akan berikatan dengan air yang ada dalam udara dan membentuk partikel yang berukuran lebih besar sehingga mudah mengendap ke permukaan bumi oleh gaya tarik bumi. ${ }^{6}$

Beberapa faktor alam yang turut mempengaruhi seperti angin, kelembaban dan suhu. ${ }^{1}$ Suhu dapat menyebabkan polutan dalam atmosfer yang lebih rendah dan tidak menyebar, peningkatan suhu dapat menjadi katalisator atau membantu mempercepat reaksi kimia perubahan suatu polutan udara. ${ }^{10}$

Berdasarkan penelitian yang di lakukan oleh Titik Istirokhatun, dan Sudarno (2014) bahwa selama dilakukan penelitian yaitu suhu berbanding terbalik 
terhadap konsentrasi CO artinya peningkatan suhu diikuti oleh penurunan konsentrasi CO. Pada saat suhu tinggi sinar matahari yang diterima akan mengakibatkan pemuaian udara. Hal ini menyebabkan terjadinya dispersi polutan sehingga konsentrasi CO akan rendah. Pengaruh kelembaban selama dilakukan penelitian yaitu kelembaban berbanding lurus terhadap konsentrasi $\mathrm{CO}$ artinya ketika kelembaban meningkat maka konsentrasi CO juga meningkat. Pada kelembaban udara yang tinggi menyebabkan terbentuknya lapisan udara dingin, dimana zat pencemar akan terakumulasi dan dispersi zat akan terhambat sehingga konsentrasi CO tinggi. Pengaruh kecepatan anginselama dilakukan penelitian yaitu kecepatan angin berbanding terbalik terhadap konsentrasi $\mathrm{CO}$ artinya semakin tinggi kecepatan angin maka konsentrasi $\mathrm{CO}$ akan kecil. Semakin cepat angin bertiup ke suatu arah sehingga luas sebaran daerah semakin luas dan konsentrasi CO akan rendah. ${ }^{4}$

Menurut Elsari (2015) konsentrasi gas CO sebanyak 30 ppm apabila dihirup manusia selama 8 jam akan menimbulkan rasa pusing dan mual. Konsentrasi gas $\mathrm{CO}$ yang tinggi di dalam uap rokok menyebabkan kandungan $\mathrm{COHb}$ dalam darah menjadi meningkat. ${ }^{2}$

Menurut asumsi peneliti, adanya pengaruh uap rokok elektrik terhadap iualitas udara disebabkan karena kandungan berbahaya yang terdapat dalam rokok elektrik yang dikeluarkan melalui uap rokok elektrik. Hal ini sejalan dengan penelitian Dr. Benard Dreyer, Presiden Amrican Academy of Pediatricts, mencatat bahwa bahan-bahan dalam cairan vaping dapat menyebabkan kerusakan karena kandungan formalin dan asetaldehida dalam uap yang dihasilkan beberapa cairan rokok elektrik. Di dalam rokok elketrik terdapat tabung berisi larutan cair yang bisa diisi ulang. Larutan ini mengandung nikotin, propinel glikol, gliserin, dan perasa. Larutan ini dipanaskan kemudian muncul uap selayaknya asap. Kandungan berbahaya lainnya yang terdapat dalam rokok elektrik, yakni logam berat, mengandung kromium dan nikel yang banyak, terdapat kandungan dietilen dan nitrosamine, asap dari e-rokok ini juga akan menimbulka aerosol yang beriso buruk bagi udara. ${ }^{13}$

\section{KESIMPULAN DAN SARAN}

Berdasarkan hasil penelitian yang dilakukan di cafe komunitas vape Kota 
Parepare mengenai pengaruh uap rokok elektrik terhadap kualitas udara ambien pada lingkungan pengguna rokok elektrik, dapat disimpulkan bahwa: ada pengaruh uap rokok elektrik terhadap kualitas udara ambient di lingkungan pengguna rokok elektrik Kota Parepare. Peneliti menyarankan bagi pengelola cafe, hendaknya dalam ruangan dilakukan pemasangan alat pengisap uap atau exhaust fan agar polusi parameter pencemar udara tidak mengendap di dalam ruangan tertutup maupun ruangan terbuka, bagi instansi kesehatan terkait, sebaiknya dilakukan sosialisasi mengenai bahaya yang terkandung dalam rokok elektrik maupun uap rokok elektrik yang dihasilkan di lingkungan sekitar cafe pengguna rokok elektrik, bagi pengunjung cafe, sebisa mungkin tidak berada dalam ruangan terlalu lama agar tidak terpapar lebih lama dengan parameter pencemaran.

\section{DAFTAR PUSTAKA}

1. Dahlan, E. N, Studi Kemampuan Tanaman dalam Menyerap Timbal Emisi dari Kendaraan Bermotor. Tesis, Bogor : Pasca Sarjana Institut Pertanian Bogor; 2010.

2. El Sari. Dampak Pencemaran Udara. 2015. [Serial online] Available at :https://dosenbiologi.com/lingku ngan/dampak-pencemaran-udara [Diakses tanggal 06 April 2018]

3. Ilmu Geografi. Ciri udara Bersih dan Sehat Beserta Penjelasannya. 2018. [Serial online] Available at https://ilmugeografi.com/ilmubimu/udara/ciri-ciri-udara-yangbersih-dan-sehat. [Diakses tanggal 04 April 2018]

4. Istirokhatun, T., \& Sudarno, S. Pengaruh Jumlah Kendaraan Dan Faktor Meteorologis (Suhu, Kelembaban, Kecepatan Angin) Terhadap Peningkatan Konsentrasi Gas Pencemar $\mathrm{No}_{2}$ (Nitrogen Dioksida) Pada Persimpangan Jalan Kota Semarang. Jurnal Teknik Lingkungan; 2014 : 3(1), 1-10.

5. Maharani, Dian. Artikel Merokok Turunkan Kualitas Sperma. 2016. [Serial online] Available at www. nationalgeographic.co.id. [Diakses tanggal 06 April 2018]

6. Prabu. Aspek Klimatologi Pencemaran Udara. 2009. [Serial online] Available at

https://putraprabuwordpress.com/2009/ 01/02/aspek-klimatologi-pencemaranudara/ [Diakses tanggal 26 Agustus 2018] 
7. Riskesdes. 2013. Badan Penelitian dan Pengembangan Kesehatan Kementrian Kesehatan RI Tahun 2013. [Serial online] Available at : https://www.google.com/search?q=risk esdas $+2013 \&$ ie $=u t f-8 \& o e=u t f-$ $8 \& c l i e n t=f i r e f o x-b$. [Diakses tanggal 1 Mei 2018]

8. Shibuyu,Y. Makalah rokok elektrik. 2015. [Serial online] Available at : http://yurishibuya27.blogspot. co.id/ 2015/10/rokok-elektrik.html. [Diakses tanggal 08 April 2018]

9. Taty A. Pencemaran Udara. 2009. [Serial online] Available at :: https://tatyalfiah.files.wordpress.com/ 2009/09/ pu-bab-1.pb[Diakses Tanggal 06 April 2018]
10. Wardhana. W. S. Strategi Dampak Pencemaran Lingkungan. Yogyakarta; 2012.

11. Yoga Permadi. Apa itu Vape. 2017. [Serial online] Available at : https://halosehat.com/pusatkesehatan/b erhenti-merokok/bahaya-vape-rokokelektrik [Diakses tanggal 12 Juli 2018]

12. Zainal Abidin. Kualitas Udara Kota Yogyakarta Ditinjau dari Kadar Partikulat Timah Hitam (Pb); 2009: 3: 425-431. [Serial online] Available at : https://jurnal.ugm.ac.id/ijc/article/ download/21510/14215. [Diakses tanggal 04 April 2018]

13. Zefanya Pentury. Bahaya Rokok Elektrik (VAPE) Bagi Remaja. Karya Ilmiah. Ambon: Fakultas Keguruan dan Ilmu Pendidikan; 2017. 


\section{LAMPIRAN}

Tabel 1. Distribusi frekuensi hasil pengukuran konsentrasi parameter kualitas udara ambien (SO2, NO2, dan $\mathrm{CO}$ ) pada ruangan terbuka

\begin{tabular}{ccc}
\hline & \multicolumn{2}{c}{ Ruangan Terbuka } \\
\cline { 2 - 3 } Parameter & $\begin{array}{c}\text { Sebelum } \\
(\mathrm{ppm})\end{array}$ & $\begin{array}{c}\text { Sesudah } \\
(\mathrm{ppm})\end{array}$ \\
\hline $\mathrm{SO} 2$ & 0,02 & 0,04 \\
$\mathrm{NO} 2$ & 0,025 & 0,036 \\
$\mathrm{CO}$ & 1,05 & 2,093
\end{tabular}

Sumber : Data Primer (2018).

Tabel 2.Distribusi frekuensi hasil pengukuran konsentrasi parameter kualitas udara ambien (SO2, NO2, dan $\mathrm{CO}$ ) pada ruangan tertutup.

\begin{tabular}{ccc}
\hline & \multicolumn{2}{c}{ Ruangan Tertutup } \\
\cline { 2 - 3 } Parameter & $\begin{array}{c}\text { Sebelum } \\
(\mathrm{ppm})\end{array}$ & $\begin{array}{c}\text { Sesudah } \\
(\mathrm{ppm})\end{array}$ \\
\hline $\mathrm{SO} 2$ & 0,02 & 0,03 \\
$\mathrm{NO} 2$ & 0,022 & 0,04 \\
$\mathrm{CO}$ & 0,97 & 2,05 \\
\hline
\end{tabular}

Sumber : Data Primer (2018).

Tabel 3. Distribusi frekuensi pengaruh uap rokok elektrik terhadap kualitas udara ambien di ruangan terbuka

\begin{tabular}{ccc}
\hline & \multicolumn{2}{c}{ Ruangan Terbuka } \\
\cline { 2 - 3 } Parameter & $\begin{array}{c}\text { Jumlah selisih } \\
(\mathrm{ppm})\end{array}$ & $\begin{array}{c}\text { Peningkatan } \\
(\%)\end{array}$ \\
\hline $\mathrm{SO} 2$ & 0,02 & 50 \\
$\mathrm{NO} 2$ & 0,011 & 30,56 \\
$\mathrm{CO}$ & 1,043 & 49,83 \\
\hline
\end{tabular}

Sumber : Data Primer (2018). 
Tabel 4. Distribusi frekuensi pengaruh uap rokok elektrik terhadap kualitas udara ambien di ruangan tertutup

\begin{tabular}{ccc}
\hline & \multicolumn{2}{c}{ Ruangan Tertutup } \\
\cline { 2 - 3 } Parameter & $\begin{array}{c}\text { Jumlah selisih } \\
(\mathrm{ppm})\end{array}$ & $\begin{array}{c}\text { Peningkatan } \\
(\%)\end{array}$ \\
\hline $\mathrm{SO} 2$ & 0,01 & 33,33 \\
$\mathrm{NO} 2$ & 0,018 & 45 \\
$\mathrm{CO}$ & 1,08 & 52,68 \\
\hline
\end{tabular}

Sumber : Data Primer (2018). 